\title{
O EMPREGO DE PRÁTICA COM BASE EM CRITÉRIO PARA APERFEIÇOAR A SEGURANÇA NA TRANSFERENCIA DE RESIDENTES DE CASAS PARA IDOSOS: UMA ANALISE DE COMPONENTES MODIFICADA E EXPLORAÇÕES SOBRE A AQUISIÇÃO DA HABILIDADE
}

\section{USING CRITERION-BASED REHEARSAL TO IMPROVE THE SAFETY OF TRANSFERRING NURSING HOMERESIDENTS: A MODIFIED COMPONENT ANALYSIS AND EXPLORATION OF SKILL ACQUISITION}

\author{
Jeanine Plowman ${ }^{1}$ and Jon S. Bailey \\ FLORIDASTATE UNIVERSITY
}

\begin{abstract}
RESUMO
As técnicas de levantamento empregadas por quatro assistentes de enfermagem certificadas foram examinadas por meio de uma análise de componentes modificada. Foram conduzidos dois procedimentos de treino em serviço. $\mathrm{O}$ primeiro incluía esclarecimento da tarefa e modelação do comportamento, semelhantes aos empregados no treinamento prévio de enfermagem. O segundo procedimento incluía uma sessão de prática do comportamento, com base em critério, e feedback. Uma fase final de contingência para o grupo foi implementada, com a finalidade de manutenção do comportamento. Foi demonstrado um aumento nas técnicas de levantamento eficazes, independentemente da fase. O maior efeito imediato ocorreu depois da modelação do comportamento e do feedback, mas uma mudança duradoura no comportamento foi demonstrada durante a fase de contingência de grupo. Foram apontadas e discutidas as implicaçōes relativas a intervençōes que incluem componentes múltiplos, comportamento de segurança e cuidados de saúde em geriatria.
\end{abstract}

Palavras-chave: análise de componentes, treino baseado em critério, residências para idosos, casa de repouso, contingência de grupo, feedback, segurança, levantamento

\begin{abstract}
Lifting techniques of 4 certified nursing assistants were examined using a modified component analysis. Two in-service training procedures were conducted. The first included task clarification and behavior modeling, similar to that used in previous nursing training. The second procedure included a criterion-based behavior rehearsal and feedback session. A final group contingency phase was implemented for behavior maintenance purposes. An increase in effective lifting techniques was demonstrated regardless of phase. The largest immediate effect occurred following the behavior modeling and feedback in-service, but sustained behavior change was demonstrated during the group contingency phase. Implications regarding multi-component interventions, behavior-based safety, and geriatric healthcare are discussed. lifting

Key-words: component analysis, criterion-based training, nursing home, group contingency, feedback, safety,
\end{abstract}

1 Corresponding Author: Jeanine Plowman, Department of Psychology Florida State University Tallahassee, FL 32306-1270. Phone: (850) $321-1661$. Email: plowman@psy.fsu.edu 
Quality of care for the elderly is an important issue for our culture. Bowers and Beckner (1992, p.360) have noted "The quality of care in long-term facilities has increasingly come under serious scrutiny by researchers, legislators, and the public". With an expected increase in the number of nursing home residents expected in the next 50 years, particularly those with Alzheimer's Disease and other forms of dementia, it is crucial to promote the safety and health of both caregivers and residents (Beck, Ortigara, Mercer \& Shue, 1999).

Part of supporting safety and health includes using proper lifting technique, as both caregiver and resident are at risk of injury, which has been a long-standing issue in business and industry. Back injuries appear to be the most frequent type of injury due to improper lifting technique. These injuries are a serious concern for geriatric health care facilities, specifically nursing homes (U.S. Department of Health and Human Services, 1988). As a regular part of a Certified Nursing Assistant's (C.N.A.'s) daily routine, safe transfer technique is essential in maintaining health not only for themselves, but also for the ultimate care and prevention of injury to the residents. Injuries to C.N.A.s occur most often while transferring and maneuvering residents (Lee \& Chiou, 1994). Occupational low back pain is also a major concern for nursing personnel (Garg \& Owen, 1992) and related injuries are the most expensive in terms of workers' compensation claims and lost work time (Lattimore, Stephens, Favell \& Risley, 1984).

Most studies focusing on lifting have been conducted within the area of ergonomics. Typical investigations of back injury prevention involve examining musculoskeletal problems (see King, 1993, for a review). However, these studies have been conducted largely by ergonomic researchers in facilities that rarely have the means to apply the interventions suggested because of low funding, practicality, and limited resources. Health care workers, specifically aides, often report inadequate training (Garland \& Schrim, 1998).

Beck et al. (1999) published a review of C.N.A. dementia care training programs. The authors state that there are many anecdotal reports but few empirical studies that specifically evaluate training programs for C.N.A.s. Most studies reviewed focused on in-service training while others, such as Stevens et al. (1998) discussed integrated behavioral skills training using such techniques as direct observation. Stubbs, Buckle, Hudson, and Rivers (1983) discussed the role of instructional training in techniques of manual handling to reduce back pain. Their results indicated that while the average nursing assistant receives three hours of instruction, no significant reduction in the occurrence of back pain was observed. Stubbs et al. suggested a more rigorous ergonomics emphasis and a focus on the acquisition of skills in a controlled setting.

Burgio and Scilley (1994) suggested that several components should be included in effective staff training programs: knowledge assessment (paper and pencil assessment administered before and after an in-service training procedure), in-service competency assessment (providing a task analysis, role play), and in-vivo competency assessment (demonstrating skill and receiving feedback). Sperbeck \& Whitbourne (1981) advocate the use of verbal and written instructions, skill modeling, and trainee role-playing. Repeatedly, recommendations for further research in this area of training revolve around evaluating the effects of the learning environment on the implementation of safety skills.

Previous studies with a behavioral orientation have reported an increase in safe lifting behavior by health care workers after feedback (Alavosious \& Sulzer-Azaroff, 1985; Alavosious \& Sulzer-Azaroff, 1990; Pyles, 1992). These studies provide empirical evidence on how to change and maintain safe lifting techniques of health care workers, but they focus only on feedback interventions. Alavosious and Sulzer-Azaroff $(1985,1990)$ targeted one-person transfers in a state residential school for developmentally disabled students, while Pyles (1992) evaluated two-person resident transfers in an Intermediate Care Facility for the Mentally Retarded, but there are no reports of behaviorally oriented investigations of training safe lifting behavior in residential nursing homes. 
While there are numerous research articles to be found using feedback as a behavioral safety intervention (Austin, Kessler, Riccobono, \& Bailey, 1996; Babcock, SulzerAzaroff, Sanderson, \& Scibak, 1992; Parsons, Reid, \& Green, 1996; Reid \& Parsons, 1996; Richman, et al., 1988), many attempts to improve safety have used package or multi-component interventions (those containing three or more interventions), (Krause, Hidley, \& Lareau, 1984). However, multi-component interventions have limited value in scientific research because they usually do not identify one specific influence on, or function of, behavior, but rather a combination of several variables. It is therefore possible for one element of a multi-component intervention to have caused experimental effects and performance changes while other variables are simply extraneous. Under these circumstances, claims cannot be made indicating which component(s) of the intervention was most effective (Barnette, 1998).

Several studies have examined the use and effectiveness of behavior rehearsal, a common element in multi-component intervention, (Faw, et al., 1981; Gladstone \& Spencer, 1977; Miltenberger, Fuqua, \& Woods, 1998) to change various behaviors. However, these studies examined the effectiveness of this intervention as part of a package rather than investigating independent interventions. Studies by Komaki, Heinzmann, and Lawson (1980), Reber and Wallin (1983), and Reber, Wallin, and Chhokar (1990), focused on component analysis research employing training, goal setting, and feedback in various manufacturing settings. All demonstrated effectiveness in separating multicomponent interventions. However, little safety research has included the element of criterion-based behavior rehearsal to establish fluency and mastery of skills that have been acquired (Neef, 1995; Stein, 1986). Examples of behaviors targeted for skill acquisition and mastery include toilet training (Azrin \& Foxx, 1971) and menstrual care (Richman, Reiss, Bauman, \& Bailey, 1984). These studies focused on persons with developmental disabilities. Further research is needed on criterion-based acquisition in organizational settings, particularly in geriatric healthcare facilities such as nursing homes.

In order to examine in-service training procedures of geriatric healthcare workers and determine which elements of a multi-component intervention are effective, the present modified component analysis was conducted.

\section{METHOD}

\section{Setting and Participants}

This study was conducted in a privately owned, 120 bed skilled-level nursing home located in a mid-sized southern city in the U.S. Observations were conducted in the dinning room area where dependent variables could easily be seen. The primary participants included 4 female certified nursing assistants. Ages ranged from 25 to 49 years, with work experience ranging from 2 months to 14 years.

The secondary participants included 4 dementia unit residents of the facility, all female. Their ages ranged from 84 to 100 years. All residents were diagnosed with dementia; three with Alzheimer's disease. These participants had resided in the facility from 4 months to 8 years. Dependent Variables

A one-person stand-pivot transfer, as indicated by the facility to be main cause of transfer related injuries, was separated into 18 steps: 1) back belt visible and fastened;2) obstacles removed from transfer pathway; 3) chair positioned close to transfer surface; 4) chair angle set; 5) both chair brakes locked; 6) resident informed of action; 7) weight tested; 8) resident prompted to scoot to edge; 9) resident prompted to lean forward; 10) arms bent; 11) feet position shoulder-width apart, toes out; 12) hand position around the back, avoiding armpit; 13) knees bent; 14) shoulder/hip alignment maintained, no twist at the waist; 15) back angle not more than half way; 16) balance maintained; 17) resident placed down gently; 18) resident held until stable. The task analysis and corresponding definitions were developed in collaboration with the facility's physical therapist and by reviewing relevant research literature (Alavosious \& Sulzer-Azaroff, 1985; Carr \& Shepard, 1987(1997 in refs); Garg \& Owen, 1992; 
Kjellberg et al., 2000; Pyles, 1992). The lifting behavior of the nurses was observed and measured using a task analysis checklist, scored as "safe", "unsafe", or "undetermined" by trained observers.

A secondary measure involved consumer satisfaction/ social validity. At the conclusion of the each phase, C.N.A.s completed a questionnaire asking how they liked the intervention, if they thought it was useful, if they thought residents were benefiting from safer transfers $\&$ increased communication regarding the transfer process itself. Numerical values were given to each response, providing a weighted value (Strongly Disagree $=0$, Disagree $=1$, Undecided = 2, Agree = 3, Strongly Agree = 4).

\section{Reliability}

Reliability data were collected on C.N.A. transfer behaviors. Two independent observers collected data on $40 \%$ of total observations. Occurrence reliability was calculated by dividing the number of agreements by the number of agreements + disagreements X 100 .

\section{Procedure}

In order to compare components of the package intervention, two phases of intervention were investigated. One independent variable involved task clarification and behavior modeling, and the other involved behavior rehearsal and feedback. Training was presented in the form of 2 in-service training sessions conducted by the facility's physical therapist. In-service training sessions, or training/ refresher courses, are frequently conducted by the facility. The duration of each session was approximately 1-2 hours.

Experimental Design. A multiple baseline design across subjects was implemented to evaluate the effects of each intervention. Subjects were randomly put in groups of two for in-services so they could serve as training partners for each other and rehearse lifting and being lifted. After a baseline period, the first phase was implemented. Phase 2 was implemented approximately 2 weeks following phase 1. Within 1 week of Phase 1 training for the first two participants, the second pair of C.N.A.s received P hase 1 training. The participants all went through the phases in the same sequence. At the conclusion of phase 2 , a group contingency phase was implemented out of necessity for sustaining the effects of the training. All participants received the group contingency simultaneously as so no participant received greater opportunity for incentives than others.

Task Clarification and Behavior Modeling. The first training phase involved a task clarification of one-person stand-pivot transfers. Task clarification entailed verbal explanation of the 18 safe behaviors presented on the task analysis. Due to the nature of the task, behavior modeling was used to further demonstrate appropriate (e.g., safe) lifting and transfer technique. This phase of intervention simulated the standard training procedures of C.N.A.s.

Behavior Rehearsal and Feedback. The second training phase involved behavior rehearsal and feedback. C.N.A.s were given an opportunity to practice safe transfer techniques in a controlled setting. Behavior rehearsal was criterion-based, which was determined by the facility. Each C.N.A. had to engage in 3 consecutive transfers at least 90 percent safe (across the 18 behaviors), with at least 2 of 3 opportunities of each behavior performed safely. The latter criterion was to ensure the C.N.A. was engaging in safe performance across all behaviors, not excluding or allowing for consecutive unsafe engagement in a behavior. Participants rehearsed proper transfer techniques by transferring each other. This role-play also aided the C.N.A. in understanding and recognizing the resident's role and participation in the transfer.

To ensure proper techniques were being rehearsed, intermittent verbal feedback was delivered by the physical therapist as needed. To ensure appropriate feedback was delivered, the researcher provided feedback training to the physical therapist prior to implementation.

Group Contingency. The final phase was introduced to increase, sustain and maintain performance following training. The nursing supervisor delivered on-the-floor feedback to C.N.A.s immediately after the transfer of a resident. Consequences were available based on a group 
contingency program. Reinforcers the participants preferred, as indicated by a brief reinforcer assessment, included hand lotion, \$5 coupons, cookies, candy, and antibacterial hand gel. C.N.A.s were regularly scheduled in groups of 3 during dining times. Reinforcers were distributed to the participating C.N.A.s if 2 of 3 participants were observed performing transfers at least $80 \%$ safely. This criterion was established by nursing staff.

\section{RESULTS}

Safety performance measures are reported for lifting technique by the four participants, including overall safe lifting behavior, skill acquisition data, and per-phase performance analysis.

\section{Safe Lifting Performance}

Figure 1 illustrates individual safe lifting performance for the four participants in a multiple baseline design. Consecutive transfers were recorded by average percent safe across the 18 behaviors observed. During baseline, data were stable for all participants. Mean averages equaled $59 \%, 59 \%, 62 \%$, and $53 \%$ percent,

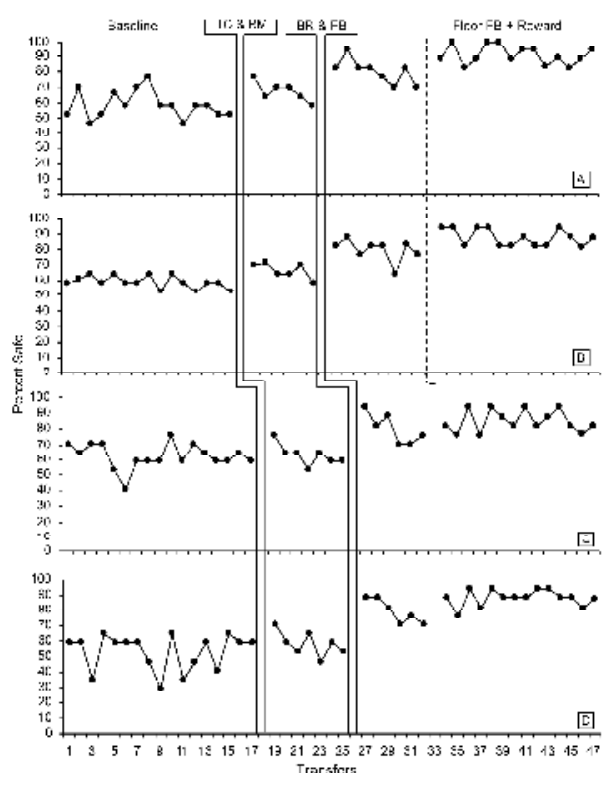

Figure 1 - Multiple Baseline Across Participants design. Each participant's performance (A-D) is represented across all phases of the study. TC = Task Clarification, BM = Behavior Modeling, BR = Behavior Rehearsal, $\mathrm{FB}=$ Feedback. respectively. Participants $\mathrm{A}, \mathrm{C}$ and $\mathrm{D}$ showed some improvement (means equal 63\%, 68\%, 67 \%, respectively) following the task clarification and behavior modeling in-service while Participant B showed minimal improvement (mean equal 58\%). All participants showed some improvement but it was not sustained. For each participant, data following the second training phase (behavior rehearsal and Feedback) showed an increase in safe transfer behavior, but all showed a trend downward. Means averaged $80 \%$ safe. During the group contingency phase, the percent safe scores were higher with all participants and this improvement was sustained for a longer period of time. Performance (average) was $88 \%$ safe.

\section{Skill Acquisition}

Figure 2 illustrates skill acquisition curves for participants $A-D$, collected during the rehearsal and feedback phase. The number of trials during the behavior rehearsal and feedback in-service ranged from 5-8, with an average of 6.5. After a few trials, performance increased quickly. Participant $\mathrm{C}$ experienced difficulty with the first 4 trials, making new errors while attempting to correct others.
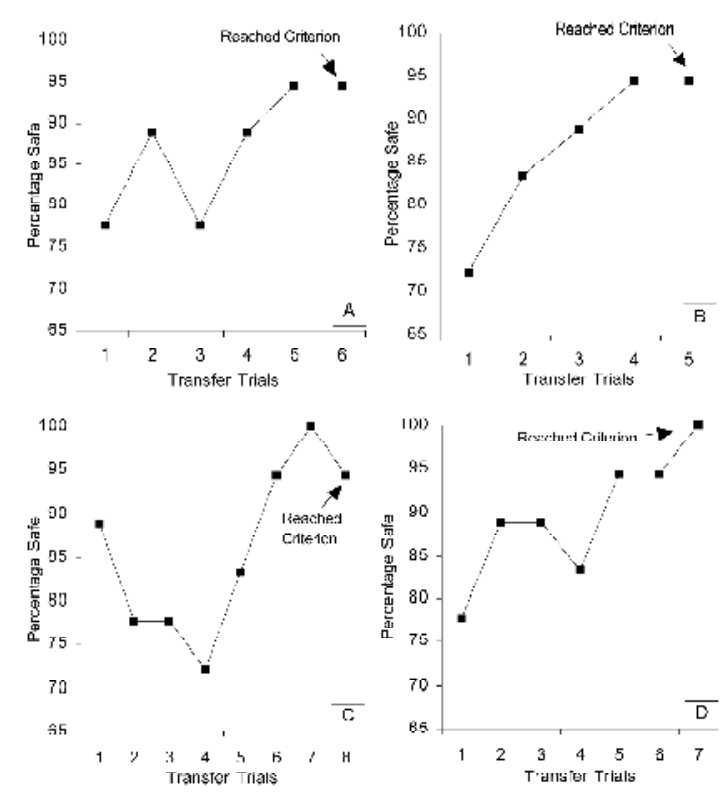

Figure 2 - Data collected during the Behavior Rehearsal and Feedback InService for each Participant (A-D). 


\section{Per-Phase Performance}

Figure 3 shows group mean performance of each of the 18 elements of the transfer technique. This presentation allows for a thorough analysis of performance per behavior as well as per phase to determine which independent variable was most indicative of changing behavior. The behaviors are arranged from unsafe to safe performance on basis of task clarification and behavior modeling (phase 1). Changes in each behavior can be seen across each phase. The task clarification and behavior modeling training was not very effective in changing the behaviors of testing the weight of the resident and prompting the resident to scoot forward. However, the behavior rehearsal and feedback in-service was more effective in changing those behaviors, and was overall more effective for improving 16 of the 18 transfer behaviors. Two behaviors (balance maintained and arms bent) were already being performed safely in baseline, causing a ceiling effect for improvement.

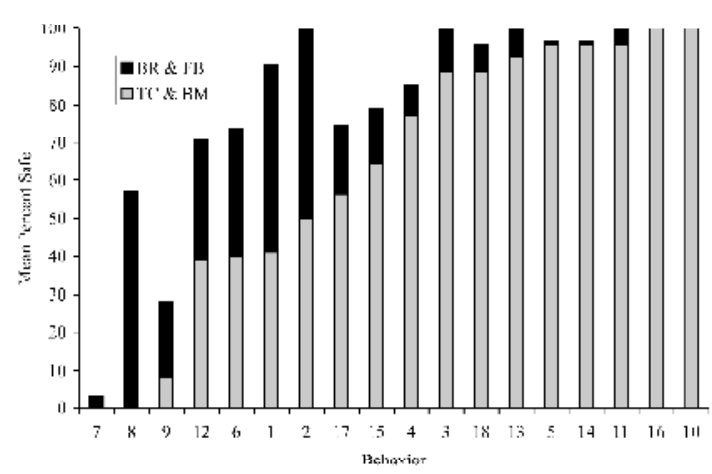

Figure 3 - Percent improvement in Behavior Rehearsal and Feedback (BR \& FB) phase compared to the Task Clarification and Behavior Modeling (TC \& BM) phase. Behaviors are sequenced from unsafe to safe during the TC \& BM phase. Total value of bars represents performance in the $\mathrm{BR} \& \mathrm{FB}$ phase.

\section{Reliability}

Reliability for each participant safe transfer behavior was calculated for each phase. Overall reliability ranged from $55-100 \%$, averaging $93 \%$ across $50 \%$ of total observations. Baseline reliability averaged $88 \%$, ranging from $86-94 \%$. Following the first and second in-service reliability averaged $93 \%$, and $92 \%$, ranging from 88 -
$96 \%$ and $87-94 \%$, respectively. During the behavior rehearsal and feedback training, reliability was taken with the physical therapist. Agreement of $98 \%$, ranging from $96-99 \%$, was reached for $85 \%$ of the total trials. During the one-month follow-up, average reliability reached $95 \%$, ranging from $91-98 \%$ agreement.

\section{Social Validity}

Figure 4 displays the participants' customer satisfaction survey results. Analysis of the surveys indicated all participants found the in-services to be beneficial. No responses were lower than "agree" on any item. The second in-service results indicate a greater positive effect, noted by more "strongly agree" responses, particularly for items such as "training can benefit other facilities" and "the residents benefited as well." Results indicate interest in behavior rehearsal and feedback in-services for other areas of work.

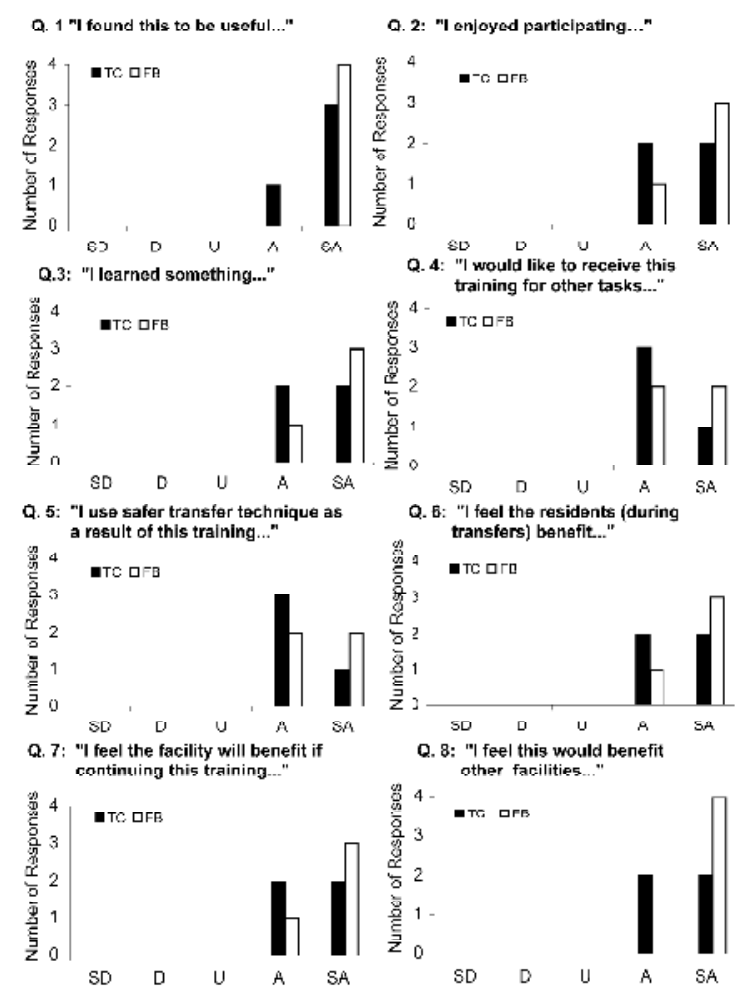

Figure 4 - Customer satisfaction survey results grouped across the 4 participants. 


\section{DISCUSSION}

The most important finding in this research is reflected in the group contingency phase. Here, safe behavior occurred at the highest rate of all phases, and the effect was sustained. Adding consequences contingent on safe transfer techniques created longer-lasting effects than antecedent training conditions alone. While the training phases demonstrated an increase in safe lifting behavior, the results were short-lived.

Results from the within-session behavior rehearsal and feedback in-service indicate an average 6.5 trials of learning before criterion was mastered. This is important to note for future use of this type of training, while our results may be reflective of the work and reinforcement histories of the participants. The average explanatory inservice training session is not sufficient to promote change, nor is it designed to test the acquisition of skill. The current data suggest that guided practice is necessary to promote safe transfer behavior. Further, to sustain these effects, contingencies (in this case, a group contingency) are needed beyond the natural consequences (e.g. avoidance of injury).

The component analysis indicates that all participants increased safe lifting behavior, with the greatest immediate effects being demonstrated following the criterion-based behavior rehearsal and feedback training. However, downward trends are evident in the data for both conditions. The specific per-phase analysis of each behavior indicates that behaviors observed to be difficult to change (e.g. most problematic) were positively affected as a result of the behavior rehearsal and performance feedback. These results are consistent with previous literature and provide further information regarding research on training nursing assistants based on skill acquisition and in vivo performance evaluation.

The elements of the training programs were designed to be beneficial not only for the C.N.A., but also for residents and the facility. Several findings from the satisfaction survey are of interest. First, all four participants responded positively to both in-services. The sample size is small, but there were no responses lower than "agree" on any item. All participants rated the second in-service more favorably than the first, based on more responses of strongly agree versus agree, suggesting not only practical effectiveness of the intervention, but preference from staff.

When conducting applied research, the importance of involving the supervisory staff in decisions is particularly important. This study actively involved numerous employees in its design, function, and implementation; staff members, rather than the researcher, carried out the study. This is relevant to the results of this study. Perhaps receiving feedback from an unknown source or from someone who does not have any supervisory position produces different results in such a hierarchical working environment as nursing.

The present study has extended the empirical evidence regarding the evaluation of training procedures for nursing assistants and effectiveness of behavior-based safety research in a new setting. These results provide evidence for healthcare facilities to implement particular training protocols to increase behavior effectively, particularly behaviors that are indicative of quality of life for multiple parties involved.

There are several limitations of this study. Due to the duration of the study and ensuing holiday season, only a few employees qualified as participants for the study (i.e. full time, availability, unit assigned to, etc.) Further, only a few residents qualified for the study (type of transfer required, special needs, etc.) This represents only a fraction of C.N.A.s and residents of the facility. Maintenance is also a limitation. Although the initial investigation involved a component analysis, a group contingency phase was implemented to correct the downtrend in safe lifting behavior. While this phase contributed to lasting effects, only a fraction of the facilities' employees participated in this research. Without including all employees facilitywide in the intervention, unsafe lifting is likely to continue. As such, cost analysis is another consideration of the present study. Due to the small sample size, it is difficult to determine the cost effectiveness of the independent 
variables, such as decrease in expenditures towards worker's compensation, related medical costs, and turnover.

This is a difficult area in which to conduct research, but certainly necessary with our rapidly changing economy and distribution of population. Our geriatric healthcare system is in need of reform, and this study provides empirical evidence of ways to improve the safety and quality of life of both healthcare workers and residents in skilled-care facilities.

\section{REFERENCES}

Alavosious, M. P., \& Sulzer-Azaroff, B. (1985). An on-the-job method to evaluate patient lifting technique. Applied Ergonomics, 16(4), 307-311.

Alavosious, M. P., \& Sulzer-Azaroff, B. (1990). Acquisition and maintenance of health-care routines as a function of feedback density. Journal of Applied Behavior Analysis, 23 (2), 151-162.

Austin, J., Kessler, M. L., Riccobono, J. E., \& Bailey, J. S. (1996). Using feedback and reinforcement to improve the performance and safety of a roofing crew. Journal of Organizational Behavior Management, 16(2), 49-75.

Azrin, N. H. \& Foxx, R. M. (1971). A rapid method of toilet training the institutionalized retarded. Journal of Applied Behavior Analysis, 4, 89-99.

Babcock, R. A., Sulzer-Azaroff, B., Sanderson, M., \& Scibak, J. (1992). Increasing nurses' use of feedback to promote infection-control practices in a head-injury treatment center. Journal of Applied Behavior Analysis, 15 (4), 621-627.

Barnette, J. (1998). Developing a science of behavioral safety: A review and critique of the literature. Unpublished critical review paper, Florida State University, Tallahassee, FL.

Beck, C., Ortigara, A., Mercer, S., \& Shue, V. (1999). Enabling and empowering certified nursing assistants for quality dementia care. International Journal of Geriatric Psychiatry, 14(3), 197-212.

Bowers, B. \& Beckner, M. (1992). Nurse's aides in nursing homes: The relationship between organization and quality. Gerontologist, 3, 360-366.

Burgio, L. D., \& Scilley, K. (1994). Caregiver performance in the nursing home: The use of staff training and management procedures. Seminars in Speech and Language, 15 (4), 315-321.

Carr, J. H. \& Shepard, R. B. (1987). Movementscience: Foundations for physical therapy in rehabilitation. Rockville, Maryland: Aspen Publishers.

Faw, G. D., Reid, D. H., Schepis, M. M., Fitzgerald, J. R., \& Welty, P. A. (1981). Involving institutional staff in the development and maintenance of sign language skills with profoundly retarded persons. Journal of Applied Behavior Analysis, 14, 411-423.

Garg, A., \& Owen, B. (1992). Reducing back stress to nursing personnel: An ergonomic intervention in a nursing home. Ergonomics, 35 (11), 1353-1375.

Garland, T. N. \& Schrim, V. (1998). Nurses' perceptions of the nurse assistant role in providing quality care in the nursing home. Gerontology \& Geriatrics Education, 18(4), 71-83.

Gladstone, B. W. \& Spencer, C. J. (1977). The effects of modeling on the contingent praise of mental retardation counselors. Journal of Applied Behavior Analysis, 10(1), 75-84.

King, P. M. (1993). Back injury prevention programs: A critical review of the literature. Journal of Occupational Rehabilitation, 3 (3), 145-158.

Kjellberg, K., Johnsson, C., Proper, K., Olsson, E., \& Hagberg, M. (2000). An observation instrument for assessment of work technique in patient transfer tasks. Applied Ergonomics, 31(2), 139-150.

Komaki, J., Heinzmann, A. T., \& Lawson, L. (1980). Effect of training and feedback: Component analysis of a behavioral safety program. Journal of Applied Psychology, 65 (3), 261-270.

Krause, T. R., Hidley, J. H., Lareau, W. (1984). Behavioral science applied to accident prevention. Professional Safety, 229, 21-27.

Lattimore, J., Stephens, T. E., Favell, J. E., \& Risley, T. R. (1984). Increasing direct care staff compliance to individualized physical therapy body positioning prescriptions: Prescriptive checklists. Mental Retardation, $22(2), 79-84$.

Lee, Y. \& Chiou, W. (1994). Risk factors for low back pain, and patient-handling capacity of nursing personnel. Journal of Safety Research, 25 (3), 135-145.

Miltenberger, R. G., Fuqua, R. W., \& Woods, D. W. (1998). Applying behavior analysis to clinical problems: Review and analysis of habit reversal. Journal of Applied Behavior Analysis, 31 (3), 447-469.

Neef, N. A. (1995). Research on training trainers in program implementation: An introduction and future directions. Journal of Applied Behavior Analysis, 28, $297-$ 299.

Parsons, M. B., Reid, D. H., \& Green, C. W. (1996). Training basic teaching skills to community and institutional support staff for people with severe disabilities: A one-day program. Research in Developmental Disabilities, 17 (6), 467-485.

Pyles, D. A. (1992). Investigation of the relative effectiveness of videotape feedback provided prior to or following lifting for improving the safety of two-person transfers in a residential care facility. Unpublished doctoral dissertation, Florida State University, Tallahassee, FL.

Reber, R. A. \& Wallin, J. A. (1983). Validation of a behavioral measure of occupational safety. Journal of Organizational Behavior Management, 5 (2), 69-77. 
Reber, R. A., Wallin, J. A., \& Chhokar, J. S. (1990). Improving safety performance with goal setting and feedback. Human Performance, 3, 51-61.

Reid, D. H., \& Parsons, M. B. (1996). A comparison of staff acceptability of immediate versus delayed verbal feedback in staff training. Journal of Organizational Behavior Management, 16 (2), 35-47.

Richman, G. S., Reiss, M. L., Bauman, K. E., \& Bailey, J. S. (1984). Teaching menstrual care to mentally retarded women: Acquisition, generalization, and maintenance. Journal of Applied Behavior Analysis, 17, 441-451.

Richman, G. S., Riordan, M. R., Reiss, M. L., Pyles, D. A., Bailey, J. S. (1988). The effects of self-monitoring and supervisor feedback on staff performance in a residential setting. Journal of Applied Behavior Analysis, 21 (4), 401-409.

Sperbeck, D. J., \& Whitbourne, S. K. (1981). Dependency in the institutional setting: A behavioral training program for geriatric staff. The Gerontologist, 21,
268-275.

Stein, K. Z. (1986). Nursing assistants learn through the competency based approach. Geriatric Nursing, 7 (4), 197-200.

Stevens, A. B., Burgio, L. D., Bailey, E., Burgio, K. L., Paul, P., Capilouto, E., Nicovich, P., \& Hale, G. (1998). Teaching and maintaining behavior management skills with nursing assistants in a nursing home. Gerontologist, 38, 379-384.

Stubbs, D. A., Buckle, P. W., Hudson, M. P., \& Rivers, P. M. (1983). Back pain in the nursing profession II. The effectiveness of training. Ergonomics, 26 (8), $767-$ 779.

U.S. Department of Health and Human Services. National Institute for Occupational Safety and

Health. (1988, September). Guidelines for protecting the safety and health of health care workers. Washington D.C.: U.S. Government Printing Office. 